In conclusion, we found that the CDSS was the optimal method to diagnose depression; however, we also found the psychiatrists' opinion alone was very accurate and therefore it is unclear from our sample whether questionnaires would appreciably help clinicians in their diagnoses.

\section{References}

Addington, D., Addington, J., Maticka-Tyndale, E., et al (1992) Reliability and validity of a depression rating scale for schizophrenics. Schizophrenia Research, 6, 201-208.

Agency for Healthcare Research and Quality (2002) Screening for Depression: Systematic Evidence Review Number 6. Agency for Healthcare Research and Quality.

Alhasnawi, S., Sadik, S., Rasheed, M., et al (2009) The prevalence and correlates of DSM-IV disorders in the Iraq Mental Health Survey (IMHS). World Psychiatry, 8, 97-109.

Broadhead, W. E., Blazer, D. G., George, L. K., et al (1990) Depression, disability days, and days lost from work in a prospective epidemiologic survey. JAMA, 264, 2524-2528.
Greenberg, P., Stiglin, L., Finkelstein, S., et al (1993) Depression: a neglected major illness. Journal of Clinical Psychiatry, 54, 419-424.

Kessler, R. C., Chiu, W. T., Demler, O., et al (2005) Prevalence, severity, and comorbidity of 12-month DSM-IV disorders in the National Comorbidity Survey Replication. Archives of General Psychiatry, 62, 617-627.

MacMillan, H. L., Patterson, C. J. S. \& Wathen, C. N. (2005) Screening for depression in primary care: recommendation statement from the Canadian Task Force on Preventive Health Care. Canadian Medical Association Journal, 172, 33-35.

National Institute for Health and Clinical Excellence (2004) Depression: Management of Depression in Primary and Secondary Care. NICE.

Taiminen, T., Ranta, K., Karlsson, H., et al (2001) Comparison of clinical and best-estimate research DSM-IV diagnoses in a Finnish sample of first-admission psychosis and severe affective disorder. Nordic Journal of Psychiatry, 55, 107-111.

Üstün, T. B., Ayuso-Mateos, J. L., Chatterji, S., et al (2004) Global burden of depressive disorders in the year 2000. British Journal of Psychiatry, 184, 386-392.

World Health Organization (2009) Iraq Mental Health Survey 2006/7 Report. WHO Regional Office for the Eastern Mediterranean.

\section{RESEARCH} PAPER

\title{
Judicial involuntary admission under the Mental Health Act in Goa, India: profile, outcome and implications
}

\author{
Anil Rane, ${ }^{1}$ Abhijit Nadkarni, ${ }^{2}$ Shilpa Waikar ${ }^{3}$ and H. A. Borker ${ }^{3}$
}

${ }^{1}$ Institute of Psychiatry and Human Behavior, Goa, India, email dranilrane@gmail.com ${ }^{2}$ London School of Hygiene and Tropical Medicine, London, UK ${ }^{3}$ Institute of Psychiatry and Human Behavior, Goa, India

We wish to thank Dr Ravindra Agrawal DPM MRCPsych for his contribution in the planning of contribution in
this paper.

\begin{abstract}
Reception order (RO) by a magistrate is a mode of involuntary admission provided under the Indian Mental Health Act of 1987. To the best of our knowledge there has been no evaluation of this provision in clinical practice. The present paper is a descriptive study through retrospective case-note review of patients admitted by way of RO to a tertiary care hospital in Goa. Compared with those admitted voluntarily, those admitted by RO tended to be single, middle aged (40-60 years old) and non-Goan; on average they had a significantly longer hospital stay than voluntarily admitted patients. Non-affective psychosis and substance use disorders were the more common diagnoses. While admissions by $\mathrm{RO}$ serve a useful role in bringing patients who are not under proper care into the mental healthcare system, they do not address the issue of aftercare.
\end{abstract}

At times, people who are mentally unwell need to be admitted to a psychiatric hospital against their will for reasons of their own safety and/ or that of others. In India, all admissions, both voluntary and involuntary, come under purview of the Indian Mental Health Act of 1987 (MHA). Under the Act there are two modes of involuntary admission: special circumstances (SC) and magisterial reception order (RO). For SC, family members or friends can request an admission if this is supported by two medical certificates. This provision is valid for a maximum of 90 days, beyond which an RO has to be obtained to continue the admission. For the RO, family members or the police may apply to a magistrate requesting the admission of a person to a psychiatric hospital. The magistrate has to be satisfied that the person is suffering from a mental disorder that needs admission for treatment or for the safety of others. The magistrate has to take into consideration the evidence of mental illness as certified by a government doctor. The RO is valid for 30 days. Within this period, the treating doctor has to certify the presence of mental illness, failing which the order lapses. If certified, the patient can be detained indefinitely until the treating doctor deems the patient fit for discharge. The patient can appeal against the order or for discharge to the magistrate or higher appellate (Gazette of India, 1987).

The objective of the present case-note review is to describe:

- the sociodemographic and clinical profile of people admitted by way of RO (comparisons are drawn with patients admitted voluntarily)

- their clinical outcomes

- the procedural details of the RO process. 


\section{Methods}

Goa, with a population of 1.5 million, is one of the smallest states in India. It has some of the best socioeconomic and health parameters in the country. Psychiatric services are provided by the public as well as the private sector. There is no active community-based psychiatric care. The onus is on the patient and family to access healthcare and for the latter to provide adequate support in the community.

In this study we retrospectively assessed the case-notes of all patients admitted by RO to a tertiary care psychiatric teaching hospital in Goa in the year 2006. Data were obtained from case-notes and RO documentation, from various magistrates' offices, which accompanied the patients. Select data were also obtained from 100 randomly selected voluntarily admitted patients in the same period. Data were collected using a structured questionnaire recording the following:

- sociodemographic details - age, gender, ethnicity, religion, marital status and education for both RO and voluntarily admitted patients

- RO procedural details - who the complainant was, the nature of the complaint, whether the RO was supported by a medical report, duration of the RO, whether the patient was eventually certified as mentally unwell and the time taken to certify

- clinical profile and discharge outcomes - clinical diagnosis and time to discharge, for both RO and voluntary patients.

Diagnoses based on ICD-10 (World Health Organization, 1992) were made during the course of the admission by the treating team, headed by a consultant.

\section{Analysis}

The counts and frequency of all the variables were recorded. Chi-square and $t$-tests were used to compare the sociodemographic profiles and clinical diagnoses of $\mathrm{RO}$ admissions with those of patients who were voluntarily admitted.

\section{Results}

Admissions to the hospital in 2006 totalled 1640, of which $109(7 \%)$ were by way of RO. Case-notes could be traced for 100 of these patients, while RO documentation was available for all 109.

The sociodemographic profile of RO patients is compared with that of voluntary patients in Table 1. Of Goan patients on RO, $62 \%$ were Christians and $50 \%$ came from a single taluka (administrative unit of the state), namely Salcete. Compared with voluntary admissions, patients on RO were significantly more likely to be middle aged (i.e. $40-60$ years old), non-Goan, Christian and unmarried.

Table 2 gives the procedural details of the RO admissions. The predominant reason for taking the patient into custody was 'nuisance', which was described as interfering with others without causing harm to person or property. Violence was

\section{Table 1}

Sociodemographic details of patients admitted under reception order (RO) $(n=100)$ compared with voluntarily admitted patients (VP) $(n=100)$

\begin{tabular}{|c|c|c|c|c|}
\hline \multicolumn{2}{|l|}{ Variable } & RO & VP & $P$ \\
\hline \multirow[t]{4}{*}{ Age } & $<18$ & 3 & 0 & \multirow[t]{4}{*}{$<0.001$} \\
\hline & $18-40$ & 50 & 75 & \\
\hline & $40-60$ & 45 & 21 & \\
\hline & $>60$ & 2 & 4 & \\
\hline \multirow[t]{2}{*}{ Gender } & Male & 73 & 64 & \multirow[t]{2}{*}{0.06} \\
\hline & Female & 27 & 36 & \\
\hline \multirow[t]{3}{*}{ Ethnicity } & Goan & 51 & 89 & \multirow[t]{3}{*}{$<0.001$} \\
\hline & Non-Goan (Indian) & 36 & 11 & \\
\hline & Foreign national & 13 & 0 & \\
\hline \multirow[t]{3}{*}{ Religion } & Hindu & 43 & 59 & \multirow[t]{3}{*}{0.003} \\
\hline & Christian & 48 & 36 & \\
\hline & Muslim & 9 & 5 & \\
\hline \multirow{4}{*}{$\begin{array}{l}\text { Marital } \\
\text { status }\end{array}$} & Married & 39 & 64 & \multirow[t]{4}{*}{$<0.001$} \\
\hline & Single & 42 & 35 & \\
\hline & Other & 6 & 1 & \\
\hline & Not known & 13 & 0 & \\
\hline \multirow{5}{*}{$\begin{array}{l}\text { Educa- } \\
\text { tion }\end{array}$} & Elementary & 9 & 6 & \multirow[t]{5}{*}{$<0.001$} \\
\hline & Pre-university & 40 & 68 & \\
\hline & University & 12 & 6 & \\
\hline & $\mathrm{Nil}$ & 11 & 20 & \\
\hline & Not known & 28 & 0 & \\
\hline
\end{tabular}

reported for 18 patients, described as harm to property or person. For all but two patients, mental illness could be certified. One of these patients was diagnosed with an intellectual disability, which does not fall in the ambit of the MHA. The other was an elderly man with no family who was admitted to the medical college hospital, from where he was referred to the study site by RO on certification of a casualty medical officer.

Table 3 describes the clinical profile and outcomes of the RO patients. While all the non-Goan RO patients and foreign nationals were admitted for the first time, 47 of the Goan RO patients had had prior admissions. The RO patients had a significantly longer hospital stay than the voluntary patients. However, no significant differences were noted in the diagnosis for which the patient was admitted.

\section{Table 2}

Reception order procedural details

\begin{tabular}{|c|c|c|}
\hline Variable & & $n(\%)$ \\
\hline \multirow[t]{6}{*}{ Complaint made by $(n=109)$} & Police & $65(59.2)$ \\
\hline & Public & $27(24.7)$ \\
\hline & Relative & $6(5.5)$ \\
\hline & Social worker & $6(5.5)$ \\
\hline & Doctor & $4(3.6)$ \\
\hline & Employer & $1(0.9)$ \\
\hline \multirow{4}{*}{$\begin{array}{l}\text { Nature of complaint } \\
(n=109)\end{array}$} & Nuisance & $70(64.3)$ \\
\hline & Wandering & $18(16.5)$ \\
\hline & Violence & $18(16.5)$ \\
\hline & Other & $3(2.7)$ \\
\hline \multirow{2}{*}{$\begin{array}{l}\text { Medical report accompanied } \\
(n=109)\end{array}$} & Yes & $102(93.6)$ \\
\hline & No & $7(6.4)$ \\
\hline \multirow[t]{2}{*}{ Mental illness certified $(n=100)$} & Yes & $98(98)$ \\
\hline & No & $2(2)$ \\
\hline \multirow{2}{*}{$\begin{array}{l}\text { Time (days) needed to certify } \\
(n=98)\end{array}$} & $<5$ & $94(96)$ \\
\hline & $>5$ & $4(4)$ \\
\hline
\end{tabular}


Table 3

Clinical profile and outcomes of patients admitted under reception order (RO) $(n=100)$ compared with voluntarily admitted patients (VP) $(n=100)$

\begin{tabular}{|l|l|l|l|}
\hline Variable & RO & VP & $P$ \\
\hline Diagnosis & & & 0.02 \\
\hline Acute psychosis & 4 & 3 & \\
\hline Schizophrenia & 29 & 35 & \\
\hline Schizoaffective disorder & 2 & 2 & \\
\hline Mania & 16 & 22 & \\
\hline Substance use disorder & 27 & 31 & \\
\hline Unspecified non-organic psychosis & 15 & 0 & \\
\hline Personality disorder & 4 & 1 & \\
\hline Dementia & 1 & 0 & \\
\hline Intellectual disability & 1 & 0 & \\
\hline No psychiatric diagnosis & 1 & 0 & \\
\hline Depression & 0 & 5 & \\
\hline Other & 0 & 1 & \\
\hline Discharge & & & \\
\hline Time to discharge, days: mean (s.d.) & $55.5(97.9)$ & $16.4(17.9)$ & \\
\hline Time to discharge, days: median & 25.5 & 10.5 & \\
\hline Range, days & $4-515$ & $1-97$ & \\
\hline
\end{tabular}

\section{Discussion}

To our knowledge this is the first Indian descriptive study of involuntary admissions by way of RO. Significantly more middle-aged, unmarried and non-Goan people were admitted by RO compared with voluntarily admitted patients. A trend towards more male admissions was noted. Involuntary admission in other parts of the world has been similarly reported to disproportionately involve young, single people (Malla et al, 1987; Bauer et $a l, 2007)$ as well as middle-aged men (Brissos et $a l$, 2007). In India, where caring for the patient in the community is largely the responsibility of the family, being unmarried may be an added disadvantage. It is not uncommon for people who are mentally ill to wander far away from home, sometimes even out of state. These individuals, on account of their abnormal behaviour, are then picked up by the police under the provisions of the MHA, resulting in an overrepresentation of people from out of state.

There was also a significant overrepresentation of Christians, probably because $50 \%$ of the Goan patients on RO came from a single taluka, one which has a high Christian representation. However, the reason for the overrepresentation of patients from this taluka is not clear.

In $94 \%$ of cases the magistrate relied upon medical certificates before issuing the RO. Such safeguards can assuage concerns raised by the psychiatric community about whether the judiciary can properly be assigned the role of determining presence of mental illness (Antony, 2000). Interestingly, the time taken to certify the presence of mental illness was less than 5 days in $96 \%$ of cases. This suggests that these patients had overt signs and symptoms to indicate mental abnormality, which in turn aided the judicial system to channel them towards the mental hospital. Therefore the RO system appears reliably to serve the purpose of getting persons with overt mental illness who are not in receipt of proper care into the mental healthcare system. However, the absence of any provision for periodic review after admission is a serious shortcoming in the MHA. In the absence of rehabilitation services, patients can languish in mental hospitals for years on end, itself a grave violation of their human rights.

Of those from our study who had previously been admitted, $75 \%$ had been brought back via a repeat $\mathrm{RO}$ admission. This raises important issues about the efficiency of aftercare and lack of social support, which need further evaluation. A community-based mental healthcare approach (which is largely missing in most parts of the country) might address such issues.

Lastly, those on RO spent significantly more time in the hospital than those voluntarily admitted. Longer stays for involuntarily admitted patients have also been reported in other studies (Malla et al, 1987). In our study it could be partly explained by the large number of patients from other states, for whom arranging travel back home was difficult, for a host of logistical and administrative reasons. This should be a matter of concern for policy-makers and resolving it would go a long way towards the timely and appropriate relocation of such patients back to the care of their loved ones.

Our paper provides some important information to fill the literature gap and at the same time raises some important issues related to legislation and policy. The MHA is an upgrade of the Indian Lunacy Act of 1912. While many changes were made, it still draws considerable criticism from practitioners of psychiatry and the public at large (Kala \& Kala, 2007). The government of India is currently drafting a new Mental Health Care Act (MHCA; Pathare \& Jagade, 2010). A provision for those with intellectual disability needs to be considered for the new MHCA, as it is excluded from the purview of the current MHA. The new MHCA will have to stipulate more safeguards to prevent the misuse of involuntary admission. It should safeguard poor and homeless people from being admitted to mental hospital in the absence of appropriate alternative resources, as was evident in one of the present series of RO admissions. While there is scope to reduce the role of the judiciary to a minimum, a system to monitor the admissions should be considered, in order to safeguard the rights of those who are mentally ill.

We can conclude that the $\mathrm{RO}$ is a useful provision in the MHA, allowing for the treatment of patients with mental illness who would otherwise have been neglected, but it does little to address the issue of continuity of care and the 'revolving door' phenomenon. We hope that the new MHCA will address these issues.

\section{References}

Antony, J. T. (2000) A decade with the Mental Health Act. Indian Journal of Psychiatry, 42, 345-355.

Bauer, A., Rosca, P., Grinshpoon, A., et al (2007) Trends in involuntary psychiatric hospitalization in Israel 1991-2000. International Journal of Law and Psychiatry, 30, 60-70. 
Brissos, S., Carita, A. \& Vieira, F. (2007) Compulsory admission to a Portuguese psychiatric hospital: retrospective study of 497 involuntary admissions. BMC Psychiatry, suppl. 1, 2

Gazette of India (1987) The Mental Health Act, Extraordinary Part II, Section I. Gazette of India. Ministry of Law and Justice, Government of India.

Kala, K. \& Kala, A. K. (2007) Mental health legislation in contemporary India: a critical review. International Psychiatry, 4, 69-71.
Malla, A., Norman, R. \& Helmes, E. (1987) Factors associated with involuntary admissions to psychiatric facilities in Newfoundland. Canadian Medical Association Journal, 136, 1166-1171.

Pathare, S. \& Jagade, J. (2010) Working Draft on Amendments to the Mental Health Act, 1987 (28 February 2010). Center of Mental Health Law and Policy, Indian law Society.

World Health Organization (1992) The ICD-10 Classification of Mental and Behavioural Disorders (10th revision) (ICD-10). WHO.

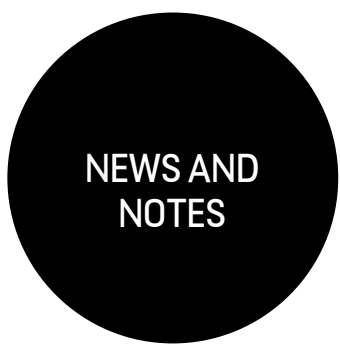

Contributions to the 'News and notes' column should be sent to ip@rcpsych.ac.uk

\section{The death of an eminent editor}

Griffith James Edwards, an eminent international expert in addictions and Honorary Fellow of the Royal College of Psychiatrists, sadly died on 13 September 2012 following a stroke. Griffith's interest in substance misuse in general and in alcohol misuse in particular started from the 1960s, and led to the establishment of the Addiction Research Unit at the Institute of Psychiatry and the Maudsley Hospital. In 1976 Griffith, with Milton Gross, published a paper with the first provisional description of alcohol dependence as a clinical syndrome. This was a landmark paper - the first time that the now familiar concept of substance dependence had been articulated. It demonstrated several facets of Griffith Edwards: his intellect, his powers of analysis and conceptual thought and his ability to articulate complex ideas. He was also very supportive of the College and chaired two committees and working groups, which led to the publication for the College of two very informative and well received books: Alcohol and Alcoholism: The Report of a Special Committee of the Royal College of Psychiatrists (Tavistock, 1979) and Drug Scenes: A Report on Drugs and Drug Dependence (Gaskell, 1987).

Griffith was Editor-in-Chief of the British Journal of Addiction from 1978 until 2005, taking it from just four issues per year to six and then to monthly. He established Regional Offices in Australia and America so that it is now a highly esteemed, international journal, renamed Addiction. Griffith was passionate about the journal and remained its Commissioning Editor until his death.

His career attracted many, many national and international honours. He was an Honorary Fellow of the College, and was made Commander of the British Empire (CBE) in 1987 for his services to social sciences and medicine.

The true measure of his contribution to addiction sciences is his legacy. For Griffith, with his interest in everyone and everything, his superb verbal fluency, his ability to ask the penetrating question to get to the heart of an issue, stimulated everyone around him. His death is a great loss to academic medicine and to psychiatry.

Hamid Ghodse, Editor

\section{Medical Training Initiative (MTI)}

The Royal College of Psychiatrists will be joining the Medical Training Initiative (MTI) and establishing its own scheme, thereby fulfilling its important role as the leading organisation in promoting quality training in psychiatry in the UK and abroad. The MTI is a national scheme designed to allow a small number of doctors to enter the UK from overseas so that they can benefit from training and development in the National Health Service before returning to their home countries.

\section{Pan American Division}

The Pan American Division of the Royal College of Psychiatrists hosted a grand reception at the 62nd Annual Conference of the Canadian Psychiatric Association in Montreal on 28 September 2012. The event was supported by the Canadian Psychiatric Association (which has signed a Memorandum of Understanding with the College) and was attended by more than 40 members of the Division. The event was fully funded by the College. Attendance has grown over the years and the reception is considered a valuable part of the Conference.

Dr Dhanapal Natarajan, Vice Chair, Pan American Division of the Royal College of Psychiatrists

\section{Faculty of the Psychiatry of Old Age: annual bursary}

The Faculty of the Psychiatry of Old Age has established an annual bursary to enable a psychiatrist from a low- or middle-income country to attend the Faculty Annual Residential Meeting (usually held in March) in order to give an oral or poster presentation, or deliver a workshop. The bursary is intended to cover the cost of economy class travel, accommodation, free registration and attendance at the Conference Dinner, up to a maximum of $£ 1500$. Informal mentors will be identified for the bursary holder. The closing date is 30 November. Emailkkottasz@rcpsych.ac.uk.

\section{Society for Emotional Well-being Worldwide}

The Society for Emotional Well-being Worldwide (SEWW; http://www.seww.org) has evolved into a social media platform for professionals working in mental health. It facilitates networking, information exchange and collaboration through a web-based platform.

\section{British Arab Psychiatrists Association}

Several members have participated in voluntary work over the past few months. This included visiting Syrian refugee camps both in Jordan and Turkey as the unmet mental health needs of these people are great. The BAPA is keen to develop a new initiative with the College Volunteer Scheme in the Arab countries. For further information contact Dr Nadim Almoshmosh, Chair of the Association (email Nadim.Almoshmosh@nhft.nhs.uk). 